\title{
Pengaruh Macam Media Tanam dan Pemberian Ekstrak Bawang Merah (Allium cepa var ascalonicum (L). Back) terhadap Pertumbuhan Vegetatif Stek Batang Manggis (Garcinia mangostana L.)
}

\author{
The Influence of Types of Planting Media and Application of Onion Extract (Allium cepa \\ var ascalonicum (L) Back) on Vegetative Growth of Mangosteen (Garcinia mangostana \\ L.) stem cuttings \\ Igga Naintina ${ }^{1}$, Lahambui Semahu ${ }^{1}$, Susanti Indriya Wati ${ }^{{ }^{*}}$ \\ ${ }^{1}$ Program Studi Penyuluhan Pertanian Berkelanjutan, Politeknik Pembangunan Pertanian \\ Manokwari \\ *Corresponding author: susankopiholic@gmail.com
}

\begin{abstract}
Abstrak
Manggis memiliki nilai dan ekonomi yang cukup tinggi. Masalah utama tanaman manggis dalam perkembangannya adalah dalam hal penyediaan bibit. Lemahnya perakaran tanaman manggis sehingga pertumbuhannya sangat lambat. Tidak semua buah mengandung biji manggis memiliki karakteristis unik dari buah tropis lainya. Kulit buah manggis akan semakin mengeras saat buah mencapai kematangan sempurna sehingga pembibitan melalui biji akan sulit terjadi di alam. Penelitian ini bertujuan untuk mengetahui pengaruh macam media tanam dan pemberian ekstrak bawang merah terhadap pertumbuhan vegetatif stek batang manggis. Penelitian ini telah dilaksanakan di Kampung Udapi Hilir, Distrik Prafi, Kabupaten Manokwari pada bulan Maret-Mei 2021. Rancang percobaan yang digunakan dalam penelitian ini adalah Rancangan Acak Kelompok (RAK) 2 faktorial dengan pola 3x3 dan 4 ulangan sehingga memperoleh 9 kombinasi percobaan dengan 36 unit percobaan. Faktor yang pertama adalah macam media tanam yaitu tanah, arang sekam dan tanah+arang sekam $=1: 1$. Faktor yang kedua adalah lama perendaman yaitu $10 \mathrm{jam}), 12$ jam dan $\mathrm{L}_{3} 14$ jam. Menggunakan uji ANOVA dengan uji $\mathrm{F}$ (taraf 5\%) dan apabila terjadi perbedaan nyata akan dilanjutkan dengan uji BNJ taraf $5 \%$. Variabel yang diamati dalam penelitian ini adalah persentase hidup (\%), waktu tumbuh tunas (mst), jumlah tunas (helai), panjang akar (cm) dan jumlah akar (helai). Hasil penelitian menunjukkan macam media tanam tidak memberikan pengaruh nyata terhadap pertumbuhan vegetatif stek batang manggis dengan waktu tumbuh tunas tercepat pada perlakuan M0 (tanah) 2.17 MST, perlakuan macam media tanam M1 menunjukkan persentase hidup tertinggi (91.67\%) dan Jumlah tunas terbanyak (1,33 helai). Variasi lama perendaman ekstrak bawang merah tidak berpengaruh nyata terhadap pertumbuhan vegetatif stek bawang merah dengan Waktu tumbuh tunas tercepat pada perlakuan L2 (12 jam) 2 MST, perlakuan L3 (14 jam) menujukkan persentase hidup tertinggi $(91,67 \%)$ dan jumlah tunas terbanyak $(1,58$ helai).
\end{abstract}

Kata kunci: Ekstrak bawang merah, Manggis, Stek batang

\section{Abstract}

As one of the native tropical commodities, mangosteen has a high economic value and customer. The main problem of the mangosteen plant in its development is in terms of providing seeds. Weak roots of the mangosteen plant so that its growth is very slow. This is because not all fruits contain seeds. Besides that, mangosteen has unique characteristics from other tropical fruits. The skin of the orchid fruit will harden when the fruit reaches full maturity so that seeding through seeds will be difficult to occur in nature. This study aims to determine the effect of the type of planting medium and the provision of shallot extract on the vegetative growth of mangosteen stem cuttings. This research was conducted in Udapi Hilir village, Prafi District, Manokwari Regency from March to May 2021. The experimental design used in this study was a 2 factorial Randomized Block Design 
Prosiding Seminar Nasional Pembangunan dan Pendidikan Vokasi Pertanian

Politeknik Pembangunan Pertanian Manokwari, 31 Juli 2021

e ISSN : 2774-1982

DOI : https://doi.org/10.47687/snppvp.v2i1.187

(RAK) with a $3 \times 3$ pattern and 4 replications so there were 9 treatment combinations with 36 experimental units. trial. The first factor is the type of planting medium, ie $M_{0}$ (soil), $M_{1}$ ( husk charcoal) and $M_{2}($ soil + husk charcoal $=1: 1)$. The second factor is the immersion time $L_{1}(10$ hours), $L_{2}$ (12 hours) and $L_{3}$ (14 hours). The next one is tested using the ANOVA test (analysis of variance) with the F test (5\% level) and if there is a real difference, it will be followed by an honest real test (BNJ level 5\%). The variables observed in this study were life percentage (\%), shoot growth time (mst), number of shoots (strands), root length $(\mathrm{cm})$ and number of roots (strands). The research results show that the type of planting media did not have a significant effect on the vegetative growth of mangosteen stem cuttings with the fastest shoot growth time in the MO (Soil) treatment 2.17 mst, the M1 planting media type treatment showed the highest percentage of survival (91.67\%) and the highest number of shoots (1.33 strands). The variation of soaking time of shallot extract had no significant effect on the vegetative growth of shallot cuttings with the fastest shoot growth time at treatment L2 (12 hours) 2 Mst, treatment L3 (14 hours) showed the highest percentage of survival (91.67\%) and the highest number of shoots (1.58 sheet).

Keywords: Mangosteen, Onion extract, Stem cuttings

\section{PENDAHULUAN}

Manggis (Garcinia mangostana L) merupakan komoditas buah tropik yang mempunyai nilai dan peluang ekonomis yang cukup tinggi. Buah manggis dapat dikonsumsi secara langsung, juga dapat dijadikan sebagai hidangan meja, dan juga dapat diolah sebagai obat herbal. Manggis mengandung xanton yang tidak dimiliki oleh buahbuah lain sehingga dijuluki sebagai "Queen of Fruits". Jumlah produksi buah manggis di Indonesia tahun 2019 sebesar 246.476 ton, sedangkan Provinsi Papua Barat menyumbang produksi buah sebesar 17 ton (BPS, 2020). Pada kuartal I tahun 2020 nilai ekspor manggis ke China meningkat $111 \%$.

Tanaman manggis dapat diperbanyak dengan menggunakan biji atau bibit hasil penyambungan, susuan dan stek batang. Tanaman manggis yang ditanam dari biji biasanya berbunga pada umur 12 hingga 15 tahun. Sedangkan yang di tanam dari hasil sambung dapat berbuah lebih cepat pada umur 5 sampai 7 tahun. Menurut Eristo dan Ichwan dalam Patangke et al. (2020) Salah satu masalah utama tanaman manggis dalam perkembangannya adalah dalam hal penyediaan bibit. Lemahnya perakaran tanaman manggis sehingga pertumbuhannya sangat lambat.

Sedangkan dalam hal ini, ZPT yang berperan penting dalam pertumbuhan akar adalah hormon tumbuh dari golongan auksin. Auksin berperan mempengaruhi pertumbuhan, differensiasi, dan percabangan pada akar, pemanjangan batang, perkembangan buah, dominasi apikal dan berkaitan dengan phototropisme dan geotropisme (Asra et al., 2020). Auksin eksogen dapat diperoleh secara sintetis dan alami. Auksin alami salah satunya dapat diperoleh dari ekstrak bawang merah (Siskawati et al 
Prosiding Seminar Nasional Pembangunan dan Pendidikan Vokasi Pertanian

Politeknik Pembangunan Pertanian Manokwari, 31 Juli 2021

e ISSN : 2774-1982

DOI : https://doi.org/10.47687/snppvp.v2i1.187

dalam Sofyan, 2018). Selain itu, pada bawang merah yang telah dihancurkan akan terbentuk senyawa allithiamin. Senyawa tersebut dapat berfungsi memperlancar metabolisme pada jaringan tumbuhan dan dapat bersifat fungisida dan bakterisida (Wibowo dalam Asra et al., 2020).

Keberhasilan stek dalam membentuk akar harus didukung dengan media tanam yang baik. Media tanam yang baik adalah media yang mampu menyediakan air dan unsur hara dalam jumlah cukup bagi pertumbuhan tanaman. Hal ini dapat ditentukan pada media dengan tata udara dan air yang baik, mempunyai agregat yang mantap, kemampuan menahan air yang baik dan ruang untuk perakaran yang cukup (Gardner dan Mitchell dalam Mariana, 2002). Arang sekam sebagai media tanam memiliki sifat porous dan tidak dapat menggumpal/memadat sehingga akar tanaman dapat tumbuh dengan baik dan sempurna.

Desa Udapi Hilir merupakan salah satu desa definitif di Distrik Prafi, Kabupaten Manokwari. Menurut pra survey yang dilakukan penulis, manggis merupakan salah satu komoditi potensial di Prafi. Hanya saja dalam perkembangannya masyarakat kurang memahami, teknik perbanyakan bagi tanaman manggis. Hal ini dikarenakan tidak semua buah mengandung biji. Selain itu, buah manggis memiliki karakteristik yang berbeda dengan buah lainya, jika pada buah lainnya akan menjadi semakin lembek saat buah mencapai kematangan sempurna, kulit buah manggis justru akan semakin mengeras. Oleh karenanya pembibitan alami akan sulit terjadi di alam. Jika tanpa bantuan hewan atau manusia untuk mengeluarkan biji dari buah manggis tersebut. Hingga saat ini populasi tanaman manggis produktif di kampung Udapi Hilir merupakan hasil program transmigrasi pada tahun 1982.

Stek merupakan teknik budidaya vegetatif yang banyak digunakan karena dirasa lebih cepat memberikan hasil. Pemilihan media tanam dan penggunaan ZPT yang tepat merupakan salah satu faktor keberhasilan perbanyakkan vegetatif. Media tanam berfungsi sebagai penyedia hara dan menjaga kelembaban serta membantu pertumbuhan akar. Sedangkan ZPT berfungsi sebagai perangsang tumbuhnya akar dan pertumbuhan vegetatif stek. Dengan hal ini diharapkan tanaman manggis lebih mudah di budidayakan dan lebih cepat memberikan hasil.

\section{METODE}

Penelitian ini dilaksanakan pada bulan Maret sampai dengan Mei 2021 di Kampung Udapi Hilir, Distrik Prafi, Kabupaten Manokwari. Alat yang digunakan dalam penelitian ini meliputi kamera, alat tulis, cutter, plastik PE ukuran 15 x $30 \mathrm{~cm}$, gelas plastik ukuran 
Prosiding Seminar Nasional Pembangunan dan Pendidikan Vokasi Pertanian

Politeknik Pembangunan Pertanian Manokwari, 31 Juli 2021

e ISSN : 2774-1982

DOI : https://doi.org/10.47687/snppvp.v2i1.187

$14 \mathrm{oz}(9 \mathrm{~cm})$, timbangan, parutan dan kain penyaring sedangkan bahan yang digunakan batang manggis muda dengan panjang $20 \mathrm{~cm}$, media tanah, media sekam dan ekstrak bawang merah.

Rancang percobaan yang digunakan dalam penelitian ini adalah Rancangan Acak Kelompok (RAK) 2 faktorial dengan pola 3x3 dan 4 ulangan sehingga memperoleh 9 kombinasi percobaan dengan 36 unit percobaan. Faktor yang pertama adalah macam media tanam yaitu $\mathbf{M}_{0}$ (tanah), $\mathbf{M}_{1}$ (Arang sekam) dan $\mathbf{M}_{2}$ (Tanah + arang sekam = 1:1). Faktor yang kedua adalah lama perendaman yaitu $\mathrm{L}_{1}(10 \mathrm{jam}), \mathrm{L}_{2}$ (12 jam) dan $\mathrm{L}_{3}(14 \mathrm{jam})$. Yang selanjutnya di uji menggunakan uji ANOVA (analysis of variance) dengan uji $\mathrm{F}$ (taraf 5\%) dan apabila terjadi perbedaan nyata akan dilanjutkan dengan uji nyata jujur (BNJ taraf 5\%). Variabel yang diamati dalam penelitian ini adalah persentase hidup (\%), Waktu tumbuh tunas (mst), jumlah tunas (helai), panjang akar (cm) dan jumlah akar (helai).

\section{HASIL DAN PEMBAHASAN}

\section{Persentase Hidup (\%)}

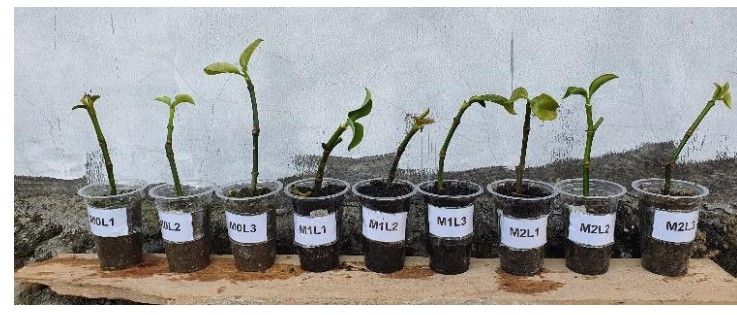

Gambar 1. Pertumbuhan Stek Batang Manggis

Persentase hidup merupakan indikator keberhasilan stek. Persentase stek hidup dilihat dari jumlah stek yang dapat hidup, ditandai dengan batang yang berwarna hijau segar, muncul tunas atau mata tunas, muncul akar. Persentase hidup stek dihitung dengan rumus : $\%$ hidup $=\frac{\text { jumlah } \text { tanaman hidup }}{\text { jumlah } \text { tanaman } \text { yang di stek }} \times 100 \%$

Tabel 1. Rata-rata persentase hidup stek

\begin{tabular}{lcccc}
\hline \multirow{2}{*}{ Media Tanam } & \multicolumn{3}{c}{ Ekstrak Bawang Merah } & \multirow{2}{*}{ Rataan } \\
\cline { 2 - 4 } & L1 & L2 & L3 & \\
\hline M0 & 50 & 75 & 75 & 66.67 \\
M1 & 75 & 100 & 100 & 91.67 \\
M2 & 50 & 75 & 100 & 75.00 \\
\hline Rataan & 58.3 & 83.3 & 91.6 & 77.78 \\
\hline
\end{tabular}

Sumber: Data Primer 2021 
Prosiding Seminar Nasional Pembangunan dan Pendidikan Vokasi Pertanian

Politeknik Pembangunan Pertanian Manokwari, 31 Juli 2021

e ISSN : 2774-1982

DOI : https://doi.org/10.47687/snppvp.v2i1.187

Berdasarkan hasil perhitungan, persentase hidup stek diperoleh sebesar 77.78\%. Berdasarkan Hasil uji analisis varian menggunakan Rancangan Acak Kelompok (RAK) Faktorial menggunakan aplikasi SPSS, menunjukkan bahwa perlakuan macam media tanam dan pemberian ekstrak bawang merah serta interaksi keduanya tidak memberikan pengaruh yang berbeda nyata terhadap persentase hidup stek. Pada Tabel 9 di atas dapat diketahui persentase tertinggi diperoleh oleh kombinasi perlakuan M1L2 (100\%), M1L3 $(100 \%)$ dan M2L3 (100\%). Sedangkan persentase terendah diperoleh dari perlakuan kombinasi perlakuan M0L1 (50\%) dan M2L1 (50\%). Sedangkan berdasarkan tabel di atas bawah persentase hidup tertinggi dari perlakuan jenis macam media tanam adalah M1 (arang sekam) 91,67\% dan persentase terendah diperoleh oleh M0 (tanah) yaitu 66,67\% sedang lama perendaman ekstrak bawang merah persentase hidup tertinggi pada perlakuan L3 (14 jam) yaitu 91,67\% persentase terendah pada perlakuan L1 (10 Jam) yaitu 58.33\%.

Hal ini diduga, kandungan auksin eksogen alami yang berasal dari ekstrak bawang merah lebih banyak terserap pada perlakuan L3 (14 jam) dibanding, kandungan auksin eksogen alami yang terserap oleh perlakuan L1 (10 Jam). Yang mana auksin sendiri berperan mempengaruhi pertumbuhan, diferensiasi, dan percabangan pada akar, pemanjangan batang, perkembangan buah, dominasi apikal dan berkaitan dengan phototropisme dan geotropism (Asra et al., 2020).

Menurut Hartus dalam Widodo (2020), faktor yang mempengaruhi persentase hidup stek antara lain adalah faktor internal dan faktor eksternal. Faktor internal yang mempengaruhi persentase keberhasilan adalah genetik varietas indukan sedangkan faktor lingkungan yang mempengaruhi pertumbuhan stek adalah perubahan cuaca (suhu) yang kurang mendukung. Pada awal pembibitan terlihat pertumbuhan tunas yang cukup baik. Pada menjelang akhir pengamatan cuaca lingkungan menjadi cukup panas.

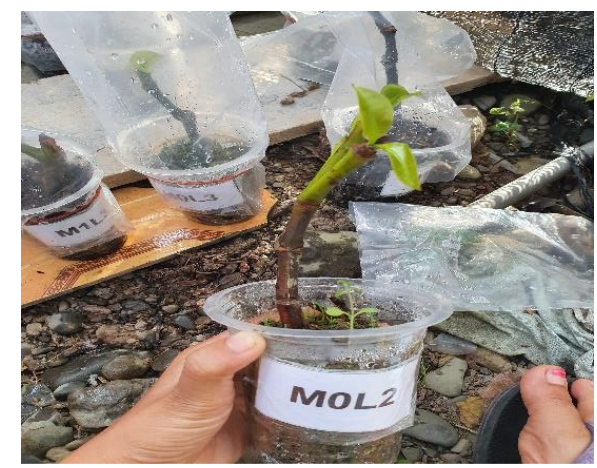

Gambar 2. Stek Menunjukkan Indikasi Kebusukan 
Prosiding Seminar Nasional Pembangunan dan Pendidikan Vokasi Pertanian

Politeknik Pembangunan Pertanian Manokwari, 31 Juli 2021

e ISSN : 2774-1982

DOI : https://doi.org/10.47687/snppvp.v2i1.187

Pada pengamatan 7 mst stek mulai menunjukkan gejala indikasi kebusukan pada stek yang telah bertunas ditandai dengan pangkal stek mulai berwarna cokelat. Hal ini diduga karena suhu yang terlalu tinggi sehingga membuat stek busuk. Hal ini sesuai dengan pernyataan Wati (2011) bahwa persentase hidup berkaitan dengan faktor ekologi yaitu lingkungan yang di dalamnya mencakup pengaruh suhu, kelembaban keadaan media, cahaya matahari, serta cukup hara dan mineral. Hal ini juga sesuai dengan pernyataan Hartmart dalam Widodo et al. (2016) suhu yang terlampau tinggi dapat mendorong perkembangan tunas melampaui perkembangan perakaran dan meningkatkan laju transpirasi. Komposisi hara yang tidak lengkap serta belum munculnya akar pada bahan stek menyebabkan tanaman hanya mengandalkan cadangan makanan yang berasal dari dalam tanaman itu sendiri sehingga lama kelamaan tanaman akan mati dan kering karena belum mampu memanfaatkan hara yang ada di sekitarnya. Hal ini sesuai dengan pendapat Franklin dalam Widodo et al. (2016) bahwa cadangan makanan organik diperlukan untuk memulai pertumbuhan baru. Stek yang mengandung karbohidrat tinggi mampu berakar lebih baik dibanding stek yang hanya mengandung karbohidrat rendah. Persediaan karbohidrat harus cukup memenuhi kebutuhan energi untuk pembentukan jaringan.

\section{Waktu Tumbuh Tunas (MST)}

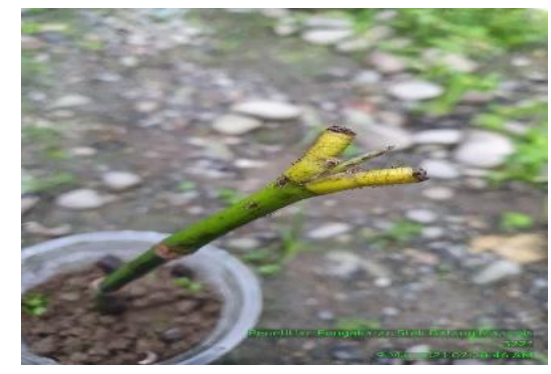

Gambar 3. Tunas Stek Batang Manggis 2 MST

Tunas merupakan bakal calon daun yang nantinya akan berfungsi sebagai tempat berlangsungnya fotosintesis tanaman, yang berguna sebagai penyedia makanan bagi tanaman. Stek dikatakan bertunas jika mata tunas yang muncul berwarna hijau dan menunjukkan bakal daun. Munculnya tunas terlebih dahulu ditandai dengan gugurnya pangkal daun lama entres, yang kemudian akan muncul tunas diantara 2 ketiak daun ataupun pada mata tunas. 
Prosiding Seminar Nasional Pembangunan dan Pendidikan Vokasi Pertanian

Politeknik Pembangunan Pertanian Manokwari, 31 Juli 2021

e ISSN : 2774-1982

DOI : https://doi.org/10.47687/snppvp.v2i1.187

Tabel 2. Rata-Rata Waktu Tumbuh Tunas (MST)

\begin{tabular}{lcccc}
\hline \multirow{2}{*}{ Media Tanam } & \multicolumn{2}{c}{ Ekstrak Bawang Merah } & \multirow{2}{*}{ Rataan } \\
\cline { 2 - 4 } & L1 & L2 & L3 & \\
\hline M0 & 2.75 & 2 & 1.75 & 2.17 \\
M1 & 2.25 & 1 & 4 & 2.42 \\
M2 & 1.25 & 3 & 2.5 & 2.25 \\
\hline Rataan & 2.08 & 2.00 & 2.75 & 2.28 \\
\hline
\end{tabular}

Sumber: Data Primer 2021

Berdasarkan tabel diatas, rata-rata umur tumbuh tunas tercepat dalam perendaman ekstrak bawang merah pada perlakuan L2 (12 jam) yaitu 2 MST. Sesuai penelitian yang dilakukan oleh Wibowo (2020) dalam penelitiannya mengatakan bahwa pemberian ekstrak bawang merah pada stek batang lada menunjukkan hasil terbaik terhadap persentase hidup stek yaitu $85,64 \%$, umur tumbuh tunas (23,67 hari), jumlah tunas (1,85 tunas), jumlah daun dan jumlah akar pada batang stek lada pada perendaman ekstrak bawang merah selama 12 jam. Ekstrak bawang merah mengandung auksin dan thiamin yang dapat meningkatkan pertumbuhan dan perkembangan tanaman. Auksin yang terkandung di dalam ekstrak bawang merah bekerja dengan merangsang sel-sel meristem apikal batang dan pucuk batang. Sesuai dengan Artanti dalam Wibowo (2012), bahwa salah satu peran auksin adalah menstimulasi munculnya tunas baru dan merangsang perpanjangan sel pada pucuk.

Berdasarkan hasil analisis statistika menggunakan uji ANOVA, bahwa masingmasing perlakuan terhadap variabel independen waktu muncul tunas tidak berbeda nyata antara perlakuan media tanam maupun lama perendaman. Hal ini diduga oleh pemilihan entres stek cenderung seragam baik bagian batang maupun panjang entres. Bahan stek juga berasal dari 1 pohon indukan. Dimana bahan stek yang digunakan adalah entres bagian muda (pucuk) dengan panjang seragam $20 \mathrm{~cm}$. sehingga waktu tumbuh tunas diduga menjadi cenderung seragam. Perlakuan sungkup juga diduga menjadi faktor pendukung percepatan waktu tumbuh tunas, hal ini sejalan dengan pernyataan Putri et al. (2017) bahwa sumber bahan stek tidak memberikan pengaruh yang nyata terhadap jumlah daun baru. Hal ini diduga karena pertumbuhan daun lebih dipengaruhi oleh faktor lingkungan. Sejalan dengan pernyataan Emmyzar dan Yulius dalam Putri et al. (2017) bahwa tanaman nilam respon terhadap naungan, nilam yang ditanam di bawah naungan mempunyai daun yang rimbun, sebaliknya yang ditanam pada lahan terbuka memiliki pertumbuhan daun yang kurang rimbun dengan habitus yang lebih kecil. 
Prosiding Seminar Nasional Pembangunan dan Pendidikan Vokasi Pertanian

Politeknik Pembangunan Pertanian Manokwari, 31 Juli 2021

e ISSN : 2774-1982

DOI : https://doi.org/10.47687/snppvp.v2i1.187

\section{Jumlah Tunas (Helai)}

Berdasarkan analisis varian dari Rancangan Acak Kelompok (RAK) Faktorial dengan perlakuan macam media tanam serta lama perendaman ekstrak bawang merah tidak berpengaruh nyata terhadap jumlah tunas bahan stek. Hal ini diduga karena asal bahan stek yang seragam, baik bagian bahan entres maupun panjang entres. Hal ini sesuai dengan hasil penelitian putri et al. (2019) bahwa bahan stek bagian ujung (muda) berpengaruh tidak nyata terhadap jumlah daun (3,2 helai) pada stek pulai. Serta sesuai dengan pernyataan Hartus dalam Wibowo (2020), faktor yang mempengaruhi persentase hidup stek antara lain adalah faktor internal dan faktor eksternal. Faktor internal yang mempengaruhi persentase keberhasilan adalah genetik varietas indukan sedangkan faktor lingkungan yang mempengaruhi pertumbuhan stek adalah perubahan cuaca.

Tabel 3. Rata-Rata Jumlah Tunas pada 8 MST

\begin{tabular}{lcccc}
\hline \multirow{2}{*}{ Media Tanam } & \multicolumn{3}{c}{ Ekstrak Bawang Merah } & \multirow{2}{*}{ Rataan } \\
\cline { 2 - 4 } & L1 & L2 & L3 & \\
\hline M0 & 0.5 & 2 & 1 & 1.17 \\
M1 & 1.5 & 0.75 & 1.7 & 1.33 \\
M2 & 0.5 & 1.25 & 2 & 1.25 \\
\hline Rataan & 0.83 & 1.33 & 1.5 & 1.25 \\
\hline
\end{tabular}

Sumber: Data Primer 2021

Berdasarkan Tabel 3, rata-rata jumlah tunas stek batang manggis adalah 1,25 helai. Penambahan ekstrak bawang merah diduga menjadi satu faktor pertumbuhan jumlah tunas atau daun. Auksin eksogen alami bawang merah membantu auksin endogen yang dimiliki oleh bahan stek untuk mendorong proses pertumbuhan tunas. Hal ini sesuai dengan pernyataan Marlin dalam Wibowo (2020), auksin yang terkandung di dalam ekstrak bawang merah berperan dalam mengaktifkan enzim-enzim yang berperan dalam pembuatan komponen sel sehingga begitu mulai terjadinya pembelahan sel maka auksin akan merangsang pembentukan sel-sel dengan cepat dan auksin mempunyai beberapa peran dalam mendukung kehidupan tanaman diantarannya adalah memicu jumlah tunas, mendorong primordial akar dan memicu pertumbuhan tunas dan pucuk. Sedangkan untuk perlakuan media tanam dinilai kurang mempengaruhi karena sampai saat pengamatan akhir tanaman belum mengeluarkan akar sehingga dapat diestimasikan pertumbuhan tunas hanya berasal dari hormon endogen dan eksogen ekstrak bawang merah. 
Prosiding Seminar Nasional Pembangunan dan Pendidikan Vokasi Pertanian

Politeknik Pembangunan Pertanian Manokwari, 31 Juli 2021

e ISSN : 2774-1982

DOI : https://doi.org/10.47687/snppvp.v2i1.187

\section{Jumlah akar (Helai)}

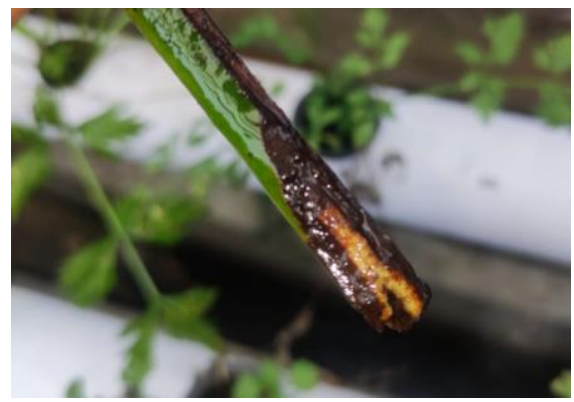

Gambar 4. Kalus pada Pangkal Stek

Berdasarkan hasil analisis pengamatan akhir menunjukkan bahwa aplikasi perlakuan macam media tanam dan lama perendaman ekstrak bawang merah serta interaksi kedua perlakuan tidak berpengaruh nyata terhadap jumlah akar. Dimana dari keseluruhan perlakuan dan kelompok belum mampu hingga memunculkan akar

Hal ini diduga akar baru akan muncul dalam waktu yang lebih lama. Media tanam arang sekam yang dinilai kurang kokoh diduga menjadi satu faktor penghambat munculnya akar. Karena bahan stek menjadi mudah goyah dan bergesekan saat proses pengamatan sehingga membuat pangkal batang rentan terluka dalam memunculkan akar. Media tanah top soil cenderung akan semakin mengeras saat disiram terus menerus sehingga akar kesulitan untuk muncul, hal ini juga menjadi satu dugaan lambatnya pertumbuhan akar. Dugaan ini sesuai dengan pernyataan Wibowo (2020) dalam penelitiannya bahwa sistem perakaran tanaman lebih dikendalikan oleh sifat genetik dari tanaman tersebut, kondisi tanah dan media tanam. Kekurangan unsur hara yang terdapat pada media tanam mengakibatkan pembentukan panjang akar dan jumlah akar tidak signifikan. Menurut Gardner dan Mitchell dalam Mariana (2002) media tanam yang baik dapat ditentukan pada tanah dengan tata udara dan air yang baik, mempunyai agregat yang mantap. media tanam juga digunakan tanaman sebagai tempat berpegangnya akar, agar tajuk tanaman dapat tegak kokoh berdiri di atas media tersebut dan sebagai sarana untuk menghidupi tanaman (Wuryaningsih, 2008).

\section{Panjang Akar (Cm)}

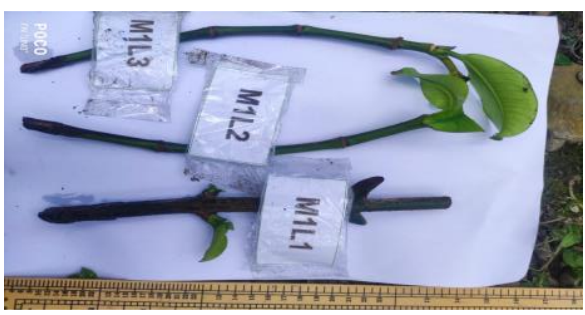

Gambar 5. Bahan Stek Belum Memunculkan Akar 
Prosiding Seminar Nasional Pembangunan dan Pendidikan Vokasi Pertanian

Politeknik Pembangunan Pertanian Manokwari, 31 Juli 2021

e ISSN : 2774-1982

DOI : https://doi.org/10.47687/snppvp.v2i1.187

Berdasarkan hasil analisis aplikasi perlakuan macam media tanam dan lama perendaman ekstrak bawang merah serta interaksi kedua perlakuan tidak berpengaruh nyata terhadap panjang akar. Dimana dari keseluruhan perlakuan dan kelompok belum mampu hingga memunculkan akar. Hal ini diduga akar baru akan muncul dalam waktu yang lebih lama. Hal ini didukung dengan bahan stek yang masih mampu memunculkan tunas dan daun serta terdapat kalus sebagai bakal akar. Menurut Dwidjoseputro dalam Saptaji et al. (2015), pembentukan akar stek dapat dirangsang oleh adanya pucuk dan daun, karena diketahui pucuk dan daun merupakan sumber penghasil hormon auksin alami (endogen). Hormon auksin yang dihasilkan dari pucuk akan ditranslokasikan kebagian bawah stek melalui jaringan floem. Terakumulasinya hormon didasar bagian stek (luka bekas potongan) maka sel kambium akan lebih cepat membelah sel membentuk kalus yang selanjutnya berkembang menjadi akar (Saptaji et al., 2015).

Media tanah + arang sekam dinilai sebagai media yang lebih potensial dalam pertumbuhan akar penelitian ini. Hal ini diduga sifat porous dan sistem drainase yang dimiliki arang sekam yang dapat mengontrol kelembaban unit penelitian. Sirkulasi udara yang baik membuat suhu di dalam sungkup tidak terlalu tinggi sehingga tanaman tidak mengalami kondisi over pertumbuhan tunas daripada pertumbuhan akar sehingga peluang hidup stek lebih tinggi. Pada penelitian ini perlakuan M1 memiliki nilai rata-rata persentase hidup tertinggi $(91,67 \%)$ dan rata-rata jumlah tunas terbanyak (1,33 helai) namun bahan stek belum dapat memunculkan akar. Media tanam arang sekam yang dinilai kurang kokoh diduga menjadi satu faktor penghambat munculnya akar karena bahan stek menjadi mudah goyah dan bergesekan saat proses pengamatan sehingga melukai bakal akar. Sedangkan media tanah top soil cenderung akan semakin mengeras saat disiram terus menerus menjadi satu dugaan lambatnya bahan stek memunculkan akar. Sehingga kombinasi kedua media tanam diduga dapat membuat tekstur media tidak terlalu rapuh dan tidak terlalu padat. Hal ini didukung oleh penelitian Wibowo (2020) pada penelitiannya, stek batang lada menunjukkan bahwa akar terpanjang dengan perlakuan jenis media tanam terdapat pada perlakuan tanah top soil + sekam padi $(12,47 \mathrm{~cm})$.

\section{KESIMPULAN DAN SARAN}

Macam media tanam tidak memberikan pengaruh nyata terhadap pertumbuhan vegetatif stek batang manggis dengan waktu tumbuh tunas tercepat pada perlakuan M0 (tanah) 2,17 MST, perlakuan macam media tanam M1 menunjukkan persentase hidup tertinggi $(91,67 \%)$ dan Jumlah tunas terbanyak (1,33 helai). Lama perendaman ekstrak 
Prosiding Seminar Nasional Pembangunan dan Pendidikan Vokasi Pertanian

Politeknik Pembangunan Pertanian Manokwari, 31 Juli 2021

e ISSN : 2774-1982

DOI : https://doi.org/10.47687/snppvp.v2i1.187

bawang merah tidak berpengaruh nyata terhadap pertumbuhan vegetatif stek bawang merah dengan Waktu tumbuh tunas tercepat pada perlakuan L2 (12 jam) 2 MST, perlakuan L3 (14 jam) menunjukkan persentase hidup tertinggi $(91,67 \%)$ dan jumlah tunas terbanyak (1,58 helai).

Berdasarkan hasil penelitian penulis, pengaruh perlakuan pada penelitian ini tidak memberikan pengaruh nyata terhadap pertumbuhan vegetatif stek batang serta belum mampu memunculkan akar. Sehingga diharapkan dilakukan penelitian lanjutan dengan komposisi media tanam serta konsentrasi ekstrak bawang merah yang lebih variatif untuk mengetahui pengaruh terhadap pertumbuhan stek batang manggis.

\section{DAFTAR PUSTAKA}

Asra, R., Samarlina, A. R., \& Silalahi, M. (2020). Hormon Tumbuhan. Jakarta: Uki press. BPS. (2020). Produksi Tanaman Buah-Buahan. https://www.bps.go.id. 13 Februari 2021

Mahfudz, I. \& M. Hidayat. (2006). Pengaruh Zat Pengatur Tumbuh Dan Media Tanam Terhadap Pertumbuhan Stek Pucuk Merbau. Jurnol Penelition Huton Tonomon, Vol. $3(1), 25-34$.

Mariana, M. (2002). Pengaruh Media Tanam Terhadap Pertumbuhan Stek Batang Nilam (Pogostemon cablin benth). Agrica ekstensia, 11 (1), 1-8.

Patangke, J., Adelina, E., \& Tambing, Y. (2020). Pertumbuhan Bibit Manggis (Garcinia mangostana L.) Dari Sumber Benih Yang Berbeda Pada Berbagai Kosentrasi Iba. $e$ J Agrotekbis, 8 (1), 209216.

Saptaji., S. \& R. Nur. (2015). Pengaruh Air Kelapa Dan Media Tanam Terhadap Pertumbuhan Stek Stevia (Stevia Rebaudiana Bertoni). Jurnal Agronida. Vol 1 (2), 83-91.

Wati, I.S. (2011). Pertumbuhan Tunas Stek Kepuh (Sterculia feotida L.) Pada Bebagai Media dan Panjang Bahan Stek. Skripsi. Universitas Sebelas Maret.

Wibowo, T. (2020). Pengaruh Jenis Media Tanam Dan Lama Perendaman Dalam Ekstrak Bawang Merah Terhadap Pertumbuhan Bibit Stek Tanaman Lada (Piper nigrum L.). Skripsi. Universitas Muhammadiyah Sumatera Utara

Widodo, S, G., Sastrowiratmo, A. \& Astusi, M. (2016). Pengaruh Tinggi Sungkup Dan Jumlah Ruas Terhadap Pertumbuhan Stek Mucuna Bracteata. Jurnal Agromasi, 1 (2). 